\title{
Study of Jugular Foramen - A Case Report
}

\author{
${ }^{1}$ Mr. K. M. Sakthivel, ${ }^{2}$ Dr. T. K. Balaji, ${ }^{3}$ Dr. A. S. Moni, ${ }^{4}$ Dr. G. Narayanan, \\ ${ }^{5}$ Dr. K. Sathish Kumar, \\ ${ }^{1}$ Lecturer, Rajas Dental College and Hospital, Nagercoil \\ ${ }^{2}$ Professor, Chettinad Hospital and Research Institute, Kelambakkam. \\ ${ }^{3}$ Professor, Rajas Dental College and Hospital, Nagercoil \\ ${ }^{4}$ Associate Professor, Sivaraj Homoeopathic Medical College, Salem \\ ${ }^{5}$ Associate Professor, Sivaraj Homoeopathic Medical College, Salem
}

\begin{abstract}
The jugular foramen at the base of the skull varies in shape and size the foramen lies at the petrous part of temporal bone and behind by the occipital bone. It's irregular in shape. Usually the right foramen is larger than the left. The variation in the foramen is observed in different racial group and sexes. The shape and size of foramen is inversely related to size of sigmoid sinus. Petrosal portion contains the inferior petrosal sinus. Sigmoid portion receives the sigmoid sinus. Intrajugular portion contains cranial nerves $I X, X$ and XI. AIM: To analyze the length and width of jugular foramen. To determine the side dominance of the foramen. MATERIALS AND METHODS: A total of 32 jugular foramen in dry adult skulls from Department of Anatomy, CHRI were used for the present study. Sagittal and transverse diameters were measured using digital vernier caliper. OBSERVATIONS: The overall dimensions of Jugular foramen were recorded on both sides. The mean transverse diameter (width) on the right and the left side were $11.779 \mathrm{~mm}$ and $10.901 \mathrm{~mm}$ respectively. The mean sagittal diameter (length) on the right and left side were $10.141 \mathrm{~mm}$ and $09.025 \mathrm{~mm}$. In $62.5 \%$ of cases the right foramen was larger, in $37.5 \%$ of cases left foramen was larger than the right. Dome was found bilaterally in $50 \%$ of cases, The unilateral presence of dome was equally distributed to both sides. Jugular process was found bilaterally in $18.75 \%$, right side $31.25 \%$ and left side in $18.75 \%$ of cases. The process was absent in $31.25 \%$ cases. Complete Septation of the foramen was found in $12.5 \%$ on right side, $6.25 \%$ on left side. Partial Septation was seen in $87.5 \%$ on right side, in $93.74 \%$ on left side. CONCLUSION: In comparison with the previous studies, the width of the Jugular foramen is slightly higher where as the length is slightly lower. There is an increase in the occurrence of bony partition compared to the previous study. Dimension, dome and Septation were significantly higher on right side than on left. Jugular foramen serves as an important land mark during surgeries of posterior cranial fossa.
\end{abstract}

\section{Introduction}

In anatomical, a foramen is considered as opening. Foraminae transmits nerves, arteries, veins, or other structures to connect one part of the body with another part. The human skull has numerous foramina through which cranial nerves, \& vessels and other structure pass. The skull bones contain foraminae that include the frontal, ethmoid, sphenoid, maxilla, palatine, temporal and occipital. There are 21 foramina present in all of the major bones of the skull. Jugular foramen is a passage or fissure between the petrous part of the temporal bone and the jugular process of the occipital bone, sometimes divided into two by the intrajugular processes. Jugular fossa contains the junction of the largest sigmoid sinus and internal jugular vein. Inferior petrosal sinus, glossopharyngeal nerve, vagus nerve, accessory nerve, meningeal branches of the ascending pharyngeal and occipital arteries are the structures passing through this foramen. The jugular foramen is a complex bony canal, which transmits vessels and nerves from the posterior cranial fossa through the base of the skull into the carotid space. According to Quain's Elements of Anatomy, the jugular foramen is described as being divided into three compartments. The anterior part is sometimes completely separated by a bony spicule (Intrajugular process).According to Cunningham's, the edge of the occipital bone forms a jugular notch and the petrous part of temporal bone is excavated to from a jugular fossa, which accommodates the superior bulb of jugular vein. According to Gray's anatomy lower border of jugular foramen are smooth and upper border sharp and notched. The margins of notch extend and divided in to three compartments.

The larger size of right jugular foramen accounts to the superior sagittal sinus draining into the right transverse sinus. But there is a very wide variation in the anatomy of the intracranial venous sinuses which accounts for variation in size and shape of jugular foramina. Complete division of the foramen by a bony septum is comparatively rare. In some cases the foramen was found to be divided into three compartments. Incomplete bony Septation, which in life is probably completed by cartilage. In syndrome of the jugular foramen (Vernet's syndrome), there is paralysis of the 9 th, $10^{\text {th }}$ and 11 th cranial nerves. These, along with paralysis of the 12 th cranial nerve (Villaret's syndrome), occur with a retropharyngeal lesion of the posterior cranial fossa. Patients 
with lesion of the jugular foramen most commonly present with combination of cranial nerve palsies, which is characterized by loss of taste sensation at the posterior third of the tongue (cranial nerve IX); vocal cord paralysis and dysphagia (cranial nerve $\mathrm{X}$ ); and weakness of sternocleidomastoid and trapezius muscle (cranial nerve XI)

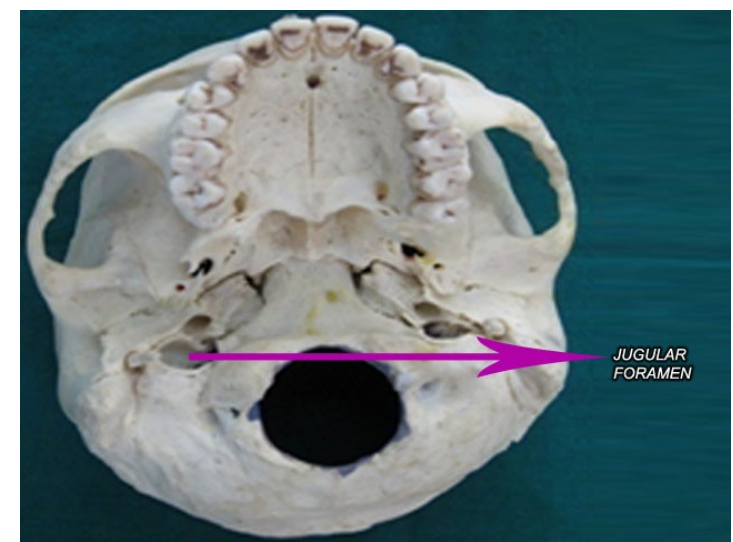

FIG - 1: Jugular Foramen With Skull (Exterior of the base of skull - Norma basalis)

\section{Materials And Methods}

A total of 46 jugular foramen were examined from 23 normal skulls. The skulls were obtained from the osteology collection of the department of anatomy, Chettinad Medical College and Research Institute Kelambakkam, Chennai. The shape of the jugular was studied. The various dimensions of the foramen were measured. The distance of jugular foramen from temporal bone (external acoustic meatus) to lateral margin of jugular foramen, from occipital bone (pharyngeal tubercle) to medial margin of jugular foramen, the anteroposterior and transverse diameter of the foramen were measured using digital vernier caliper with a precision of $0.01 \mathrm{~mm}$. Each dimension was measured thrice and the mean figure recorded. The data collected was checked for errors prior to analysis. Variation in the above dimension between right and left side was noted. The data are plotted in tabular column, through the measurements; Mean transverse diameter, mean vertical diameter, bony Septation, dome and mean distance from temporal bone and occipital bone are calculated.

Study includes 23 dried skulls from the Department of Anatomy, Chettinad Hospital \& Research Institute. Both right and left jugular foramen were analyzed in all the 23 skulls. The shapes of jugular foramen oval (fig.1a) and round (fig.1b) were observed. Both size and shapes were observed in the same skull. Most common observed round shape jugular foramen (table 1).

Table: 1: Shape Of Jugular Foramen

\begin{tabular}{|l|l|l|}
\hline Shape of the Jugular Foramen & Right Side & Left Side \\
\hline Oval & $07(15.2 \%)$ & $12(26.0 \%)$ \\
\hline Round & $16(34.7 \%)$ & $11(23.9 \%)$ \\
\hline
\end{tabular}

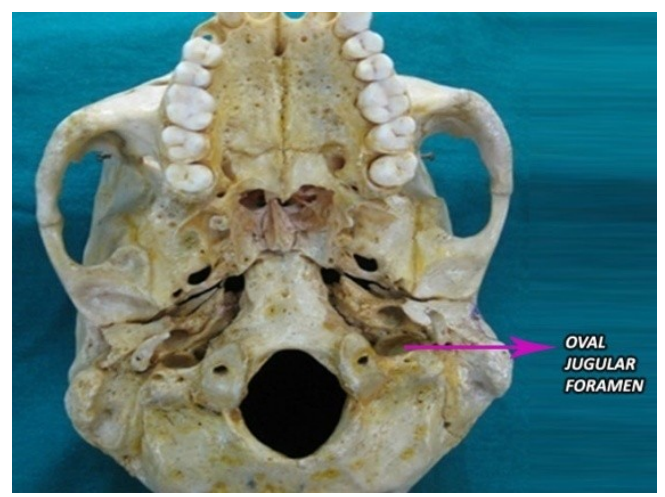

Fig - 2: Skull With Oval Shape Jugular Foramen (Exterior Of The Base Of Skull - Norma Basalis) 


\section{Diameter Of Jugular Foramen}

The vertical and transverse diameters of oval and round shaped jugular foramen were observed (fig. 2 $\& 3$ ). The values are tabulated (table $2 \& 3$ ) and through the tabulated values the mean is calculated (table 4).

Total mean transverse diameter is

- $11.16 \mathrm{~mm}$.

Total mean antero-posterior diameter is $\quad-\mathbf{0 9 . 4 4} \mathbf{~ m m}$.

Table- 2: Diameters Of Oval Shape Jugular Foramen

\begin{tabular}{|l|l|l|l|}
\hline \multicolumn{2}{|l|}{ Transverse Diameter (In mm) } & \multicolumn{2}{l|}{ Antero-posterior Diameter (In mm) } \\
\hline Right side & Left side & Right side & Left side \\
\hline 10.50 & 10.49 & 08.81 & 09.58 \\
\hline 12.13 & 09.20 & 09.74 & 07.74 \\
\hline 11.00 & 09.98 & 08.86 & 07.02 \\
\hline 13.72 & 09.49 & 07.63 & 07.82 \\
\hline 12.86 & 09.90 & 10.78 & 07.48 \\
\hline 12.88 & 10.87 & 10.43 & 07.34 \\
\hline 12.67 & 10.73 & 10.52 & 07.96 \\
\hline & 10.33 & & 07.52 \\
\hline & 10.02 & & 07.64 \\
\hline & 09.82 & & 07.22 \\
\hline & 09.97 & & 08.32 \\
\hline & 10.45 & & 08.24 \\
\hline
\end{tabular}

Table - 3: Diameters Of Round Shape Jugular Foramen (Fig.1 \& 2)

\begin{tabular}{|l|l|l|l|}
\hline \multicolumn{2}{|l|}{ Transverse Diameter (In mm) } & \multicolumn{2}{l|}{ Antero-posterior Diameter (In mm) } \\
\hline Right Side & Left Side & \multicolumn{1}{l|}{ Right Side } & Left Side \\
\hline 10.96 & 13.16 & 10.03 & 12.26 \\
\hline 13.00 & 10.27 & 12.20 & 09.15 \\
\hline 10.07 & 11.42 & 09.11 & 09.26 \\
\hline 12.30 & 12.34 & 11.65 & 10.16 \\
\hline 10.93 & 10.49 & 09.72 & 08.84 \\
\hline 11.91 & 09.99 & 13.01 & 09.00 \\
\hline 11.15 & 11.25 & 10.00 & 10.14 \\
\hline 12.07 & 12.94 & 10.53 & 10.80 \\
\hline 11.47 & 11.90 & 10.32 & 09.86 \\
\hline 11.52 & 11.35 & 09.45 & 09.54 \\
\hline 10.34 & 10.88 & 10.10 & 10.21 \\
\hline 11.11 & & 09.90 & \\
\hline 11.23 & & 09.88 & \\
\hline 11.00 & & 10.23 & \\
\hline 10.65 & & 09.62 & \\
\hline 10.87 & & 09.01 & \\
\hline
\end{tabular}

Mean Diameters Of Oval And Round Jugular Foramen

Mean transverse diameter of oval jugular foramen

Mean antero-posterior diameter of oval jugular foramen

Mean transverse diameter of round jugular foramen

Mean antero-posterior diameter of round jugular foramen

\section{$=10.89 \mathrm{~mm}$.}

$=06.78 \mathrm{~mm}$.

$=11.38 \mathrm{~mm}$.

$=10.14 \mathrm{~mm}$.

Table - 4: Combined Mean Of Oval And Round Jugular Foramen.

\begin{tabular}{|l|l|l|l|l|}
\hline Diameter & \multicolumn{2}{|l|}{ Mean \& S.D } & P-value \\
\hline \multirow{2}{*}{$\begin{array}{l}\text { Transverse diameter of oval and } \\
\text { round }\end{array}$} & $\begin{array}{l}\text { Combined } \\
\text { mean }\end{array}$ & Right & Left & \multirow{2}{*}{$0.271^{*}$} \\
\cline { 2 - 4 } $\begin{array}{l}\text { Antero-posterior diameter of oval } \\
\text { and round }\end{array}$ & $09.44 \pm 1.08 \pm 1.38$ & $11.58 \pm 1.07$ & $10.74 \pm 1.28$ & \\
\hline
\end{tabular}

* The P- value obtained is higher than the level of significance $(0.05)$ which does not bear any statistical significance.

The jugular foramen was examined with respect to size, shape, presence of a domed bony roof and bony Septation. Out of 23 skulls complete septation was observed in (39.0\%). The right jugular foramen was larger in 16 skulls $69.5 \%$ and the left was larger in 07 skulls $(30.4 \%)$ (table.5). The dome, which is related to the 
presence of the superior jugular bulb (fig.4), was present bilaterally in 10 skulls (43.4\%), unilaterally on the right side in 08 skulls (34.7\%) and on the left side in 05 skulls (21.73\%) (table.5). Out of the 23 skulls, complete septation of the jugular foramen by a bony septum (intra jugular process) was present on the right in 06 skulls (26.0\%) (fig.7), on the left in 03 skulls (13.0\%). The bony septation was sometimes partial on the right side in 17 skulls $(73.9 \%)$, on the left side in 20 skulls $(86.9 \%)$ (table.5). In life it was probably completed by cartilage or a fibrous structure.

Table.5

\begin{tabular}{|l|l|l|l|l|}
\hline Number of skull & Bilaterally & Right side & Left side & Incomplete \\
\hline $\mathbf{2 3}$ & 05 & 09 & 04 & 05 \\
\hline Percentage & $21.73 \%$ & $39.13 \%$ & $17.39 \%$ & $21.73 \%$ \\
\hline
\end{tabular}

The intrajugular process was presence bilaterally in $05(21.73 \%)$ skulls, on the right side in 09 $(39.13 \%)$ skulls, on the left side in $04(17.39 \%)$ skulls and incomplete jugular process was present in 05 (21.73\%) skulls (fig. 7) (table 10).

\section{Discussion}

In the present study the right side jugular foramen was larger than the left this accounts for the fact that the internal jugular vein passing through the right foramen might be larger than the left. It is quite possible that the superior sagittal sinus, right transverse sinus and right sigmoid sinus draining into right internal jugular vein might be enlarged. On the other side smaller inferior sagittal sinus joins with Great cerebral vein of Galen to become straight sinus and continuing as left transverse sinus, left sigmoid sinus and the left internal jugular vein might be relatively smaller. However, there is a wide variation in intracranial venous sinuses (Woodhall, 1939, Browder \& Kaplan, 1976), which accounts for variation in size and shape of the foramen.

The present study differs with respect to partial and complete septation. Partial septation was observed in $73.9 \%$ of skulls on right side and in $86.9 \%$ of skulls on left side, complete septation was observed in $26.0 \%$ on right side and in $13.0 \%$ on left side (table 5). The incidence percentage of septation is more as compared to that of previous studies. The jugular process was found bilaterally in $21.73 \%$ of skulls, unilaterally on the right side in $39.13 \%$ and in $17.39 \%$ of skulls on left side, incomplete jugular process was observed in $21.73 \%$ of skulls (table 10). With regard to formation of bony bridges in the jugular foramen the following patterns are commonly observed.

1) The jugular process of the temporal bone is situated posterior to the triangular depression (as described in gray's anatomy) of the petrous part.

2) The bony bridging of the jugular foramen is established by the contact of the intrajugular process of the temporal bone with the bony process of the occipital bone projecting either from just above the hypoglossal canal (Type I) or from posterior to the hypoglossal canal (Type II).

3) If both the processes of the occipital bone reach the intrajugular process of the temporal bone simultaneously, the jugular foramen is divided into three compartments.

4) In the case of Type I bridging, the anteromedial compartment transmits glossopharyngeal nerve, while posterolateral compartment gives passage to the vagus nerve, the spinal accessory nerve and internal jugular vein.

5) In the case of Type II bridging the anteromedial compartment contains the glossopharyngeal, vagus and spinal accessory nerve, and posterolateral compartment transmits the internal jugular vein.

6) When tripartite division of the jugular foramen occurs, the anteromedial compartment transmits the glossopharyngeal nerve, the middle compartment contains the vagus and accessory nerves, and posterolateral compartment transmits the internal jugular vein.

In the present study, Type I bridging pattern was more commonly observed. This type was unilaterally observed on the right side. Variations in the course of cranial nerves within this foramen are based on the type of bridging pattern. The fact that bridging of the jugular foramen is established by the end of fetal development serves as a strong indication to be used effectively for anthropological studies.

\section{Conclusion}

The large variations in the jugular foramen, equally reported in previous studies are possibly due to constitutional, racial and genetic factors. The total bony subdivision of the jugular foramen is not common in south Indian population. In the present study it was observed that Jugular foramen is generally larger on the right side but does not bear any statistic significance. It was also observed that the presence of jugular process with a partial dome in proximity to the jugular foramen further suggests a hypothesis that the size of jugular process was proportional to the size of dome. This accounts for accommodation of superior jugular bulb of internal jugular vein. The variations observed in present study are of immense value to ENT surgeons while performing middle ear surgeries for various jugular foramen tumors. Also the bridging patterns cause 
compression to structures passing through this foramen hence accentuating the clinical presentations of Glomus jugulare.

\section{References}

[1]. Adejuwon.S.A, Salawu.O.T, The jugular foramen and the intracranial volume; are they related? Asian J. Med Sci.2011; 3(8): 14345.

[2]. Anjali single.A, Daisy sahni.M, Morphometric study of the jugular foramen in Northwest Indian population. J. postgraduate med. 2012; 46(4):165-71

[3]. Bahar Kales.S, Jose N. Fayed, The medial wall of the jugular foramen a temporal bone anatomic study. Otolaryngology head neck surg. 2009; 141(3): 401-07.

[4]. Browder.J, Kaplan.M, Cerebral Dural sinuses and their tributaries. Springfield: Thomas. J. Anat., 1976; 36(12): 79-140.

[5]. Ekinci.N, Unur.E, Macroscopic and Morphometric investigation of the jugular foramen of the human skull. J. Anat., 1997; 72(5): 525-29.

[6]. Hatiboglu.M.T. \& Anil.A, Structural variations in the jugular foramen of the human skull. J. Anat., $1992 ; 180(1): 191-96$.

[7]. Hussain.S, Thomas.S.T, Morphological variations in the structure of the jugular foramen of the human skulls of south India. Biomedical Research. 2010; 21 (40): 349-50.

[8]. Idowu.O.E, The jugular foramina morph metric study. Folia Morphol, 2004; 63(4):419-22.

[9]. Krebs.WD \& Santos.R.D, Morphometric aspects of the jugular foramen in dry skulls of adult individuals in southern Brazil. J. Morphol, sci.2010; 27(1): 3-5.

[10]. Kapakin.S, An unusual anatomic variation of the jugular foramen with doubled posterior condylar canal. Int. J. Morphol, 2011; 29(4): 1186-88.

[11]. Patel.MM \& Singel.TC Variations in the structure of jugular foramen of the human skull in Saurashtra Region. J. Anat. Soc. India. 2007; 56(2): 34-37. 